\title{
IMPERIAL COLLEGE SIERRA LEONE EXPEDITION 1963
}

\begin{abstract}
$\mathrm{T}$ VHIS summer, Imperial College of Science and Technology is sending an expedition of undergraduate biologists to Sierra Leone. The main purpose of the expedition is to carry out a comprehensive study of the flora and fauna of the Northern Province. It is hoped to direct particular attention to the Scarcies River basin and, if possible, to the Loma Mountains. This will be the third expedition from the College to Africa in two years, others being to Nigeria and Ethiopia. The expedition is being made up of five botanists and three zoologists. Two members have had previous expedition experience and all the botanists have worked on the vegetation of the montane region of southern Yugoslavia. An extensive programme of collection and observation is being worked out. It is hoped to bring back several thousand specimens: these will be deposited either at the Kow Herbarium, the Commonwealth Mycological Institute, or the British Museum (Natural History).
\end{abstract}

In addition to the general survey, the expedition is undertaking work on behalf of the Food and Agriculture Organization. In particular, a survey will be made of indigenous food plants, and it is hoped to collect wild coffee plants of possible value for future taxonomic or breeding work. The zoologists will be primarily concerned in making observations and collections of the fauna of the area, and in particular on the Heteroptera and Coleoptera. A collection of Mollusca will be made to continue work by the Nigerian Expedition on the Mollusca of West Africa. Collections of mammal and bird para. sites will also be made, and blood smears taken for pharmaceutical purposes.

The expedition will spend approximately eight weeks in Sierra Leone, and a full report will be published. If the aims of the expedition are accomplished then further expeditions may well continue the work in future years.

P. ROGERS

\section{TROPICAL PARASITOLOGY}

$\mathrm{T}$ HIS symposium, the first regional symposium of its kind, was organized jointly by the Unesco Southeast Asia Science Co-operation Office and the Department of Parasitology, University of Singapore. It was held at the Medical School, University of Singapore, during November 5-9, 1962. It was convened under the chairmanship of Prof. R. S. Desowitz. The purpose of the symposium was to provide an opportunity for an exchange of experiences and results among research workers in the field of tropical parasitology.

The conference was attended by delegates from Aus. tralia, Ceylon, Hong Kong, India, Indonesia, Japan, Malaya, the Philippines, Singapore, Taiwan, Thailand and Vietnam. These delegates, as well as representatives from the World Health Organization and the Food and Agriculture Organization, had been invited by Unesco to attend the conference. Dr. N. Ansari, chief of Parasitic Diseases Branch, represented the World Health Organization.

The symposium opened with an address of welcome by the vice-chancellor of the University of Singapore, Dr. B. R. Sreenivasan. This was followed by an introductory address by Mr. L. Mattsson, director of the South-east Asia Science Co-operation Office, Djakarta.

The first day was taken up by a series of survey papers relating to the background and progress of work in the field of parasitology in the various countries included in the region. An interesting feature of these reports was their refreshing variety of approach. Each report, in its different way, described the background of endeavour which had resulted in the establishment of the various institutions where parasitology is studied throughout the South-east Asian region and gave details of the investigations which were being carried on. These reports constituted a valuable contribution and comprise not only a useful compilation pertaining to the history of para. sitology in this region but also an index of personnel, institutions, and bibliographies.

Although the scope of these reports was by no means uniform, it was nevertheless a prominent feature that they emphasized the need for further co-operation and interchange of ideas among parasitologists in the Southeast Asian region.

It was evident that there has been a marked improvement in the overall facilities available for research on parasitic diseases in the tropics. Places which were once little more than field stations have now become centres of basic parasitological research. The important implica. tion of this is that the most up-to-date laboratory apparatus is now within relatively easy access to the front line of research in the parasitological field, so that direct investigations on the important disease-producing parasites can be conducted. Previously, it had. so often occurred that the basic observations on morphology, physiology, immunology, etc., were restricted to parasites which could be maintained in the laboratory.

On the other hand, it was also evident that the old problems of disease and untimely death are still the main concern of parasitologists over most of the South-east Asian region. But the vigorous research programmes relating to the diagnosis and control of parasitic diseases now operating in many of the South-east Asian countries, coupled with the frequent visits being made by specialists in various fields, and the close liaison which has evidently been established with universities and research centres in other parts of the world, gives promise of a successful campaign against the protozoa, worms and arthropods which still cause such widespread disease in tropical regions.

This overall emphasis on medical parasitology is in contrast with the situation in Australia, where the parasites of domestic animals appear to comprise the most important application of parasitology, and where it is evident that funds for research in the field of veterinary parasitology far exceed those available for medical parasitology.

Three full days were devoted to research papers; these again showed a remarkable diversity of interest. Thus, there were papers of a clinical nature, some dealing with lesions and symptoms, others with method of control, epidemiology, and treatment. But there were also papers devoted to the basic principles of parasitology, such as the immunology of parasitic infections, the physiology and metabolism of parasites, as well as systematies, ecology, evolution, and phylogeny in relation to parasitic organisms.

The whole symposium achieved a balance of emphasis between, on one hand, the fundamentals of structure and function in relation to parasitism, and, on the other, the distress and hardship which parasitism involves. 